\title{
Developing a Selection Criterion for Terminal Heat Tolerance in Bread Wheat Based on Various Mopho-Physiological Traits
}

\author{
Devender Sharma*, J.P. Jaiswal, N.K. Singh, Anjana Chauhan \\ and Navin Chander Gahtyari
}

\author{
Department of Genetics and Plant Breeding, G.B.Pant University of Agriculture \& \\ Technology, Pantnagar-263145 (Uttarakhand), India
}

*Corresponding author

\begin{abstract}
A B S T R A C T
Keywords

Wheat, heat stress, Canopy temperature depression; membrane thermostability, 1000 Grain Weight, Normalizes Difference Vegetation index

Article Info

Accepted: 20 June 2018 Available Online: 10 July 2018

Wheat (Triticum aestivum L.), a staple food crop is of great commercial importance. Its production is restricted due to various abiotic stresses. There are indications that the wheat production is consistently limited by terminal heat stress. Here, performance of forty genotypes of wheat was undertaken for assessment of direct selection parameters (variability, heritability and genetic advance) and their relation with heat tolerance. The plants were sown in late planting (first fortnight of December) to expose them to terminal heat stress. Observations were recorded on fourteen morpho-physiological traits i.e. days to heading, days to maturity, grain filling duration, number of tillers per plant, spike length, grain yield per plant, 1000-kernel weight, CTD-I, CTD-II, CTD-III, NDVI-I, NDVI-II, NDVI- III and membrane thermostability. High heritability associated with high genetic advance reflected for physiological traits like canopy temperature depression and membrane thermostability. That indicated effectiveness of selection for the improvement of these traits. Moderate estimate of genetic advance (25\%-50\%) exhibited for number of tillers per plant, NDVI I, CTD (I \& II) and spike length. For all the morpho-physiological traits studied, the estimates of phenotypic variance were exhibited higher than their corresponding genotypic variances, indicating the influence of environment on the expression of these morpho-physiological characters were observed. These finding suggests the relative importance of various physiological traits in formulating the selection criteria for developing thermotolerant wheat cultivars.
\end{abstract}

\section{Introduction}

Wheat (Triticum aestivum L.), a cereal grass belong to Poaceae family and of the genus Triticum, is the world's largest cereal crop extensively grown as staple food in the world. Wheat is grown on 223.67 million hectares throughout the world, which produces 735.3 million tons of grain (USDA, 2017). It provides, on an average, $20 \%$ of daily calories and protein for 4.5 billion people (Shiferaw et al., 2013). Wheat in India is grown over an area of 30.72 million ha producing 98.30 million tonnes (ICAR-IIWBR, 2017). It occupies an inimitable position in human life as it is the major source of food and energy 
with a large number of products like chapathi, biscuits, bread and pasta, even it is a good source of fodder for animals.

Wheat production is limited by current and upcoming challenges including reduced land, reduced water availability increased temperature due to global warming under climatic shift (Fischer et al., 2002). Among these, increased temperature stress is increasingly causing a concern as the global air temperature is predicted to rise by $0.2{ }^{\circ} \mathrm{C}$ per decade, leading to temperatures $1.8-4.0^{\circ} \mathrm{C}$ higher than the current level by 2100 (IPCC 2007). Even now heat stress affects $40 \%$ of the wheat growing area of the world covering about 36 million ha (Reynolds et al., 2001). Every $1{ }^{\circ} \mathrm{C}$ rise in temperature above the optimal $28^{\circ} \mathrm{C}$ reduces wheat yield by $3-4 \%$ (Wardlaw et al., 1989).

The terminal heat stress at anthesis and grain filling stages accelerate maturity and significantly reduce grain size, weight and yield (Rane et al., 2000; Lane et al., 2007; Kosina et al., 2007). Physiological responses of wheat crop to terminal heat stress have been found to effectively determine genotype tolerance or susceptibility (Almeselmani et al., 2000). There is urgent need for immediate attention to develop heat tolerance wheat genotypes by combining different approaches.

The genetic potential of different cultivars for the presence of diversity, stability in performance are measured by statistical parameters such as mean, variance, coefficient of variation (\%), heritability and genetic gain (Ali et al., 2008). Grain yield is a complex trait and is greatly influenced by various environmental factors. Various morphophysiological traits contribute to grain yield in heat stress conditions. Each of these component traits has its own genetic systems. Therefore, it is necessary to separate the total variation into heritable and non-heritable components with the help of genetic parameters i.e. genotypic and phenotypic coefficient of variation, heritability and genetic gain (Kahrizi et al., 2010). The phenotypic variance measures the magnitude of variance arising due to genetic component and environmental factors. The heritability is a measure of the genetic relationship between parents and progeny, hence considerable research work has been carried out to incorporate desirable genes in the present wheat varieties to increase the productivity of the crop (Memon et al., 2007). Here, Morphophysiological evaluation of wheat genotypes was performed under late sown condition to assess genetic variability and develop selection criteria for developing thermotolerant cultivars.

\section{Materials and Methods}

A set 40 diverse wheat genotypes (Triticum aestivum L.) were selected (Table 1) for field experiments conducted at Dr. N.E. Borlaug Crop Research Centre of GB Pant University Agriculture and Technology, Pantnagar, India in rabi season during 2017-2018. The plants were sown in late planting (first fortnight of December) to expose them to terminal heat stress. The experiment was conducted in three replicates; in randomized block design with three rows and $23 \mathrm{~cm}$ inter row spacing. Seven morphological traits i.e. days to heading, days to maturity, grain filling duration, number of tillers per plant, spike length, grain yield per plant, 1000-kernel weight, CTD-I, CTD-II, CTD-III, NDVI-I, NDVI-II, NDVI- III and membrane thermostability. Nineteen morphophysiological traits i.e. days to heading, days to maturity, grain filling duration, plant height, peduncle length, number of tillers per plant, spike length, total number of spikelets per ear, biological yield per plant, grain yield per plant, harvest index, 1000-kernel weight

Seven morphological traits i.e. days to heading, days to maturity, grain filling 
duration, number of tillers per plant, spike length, grain yield per plant, 1000-kernel weight and three physiological traits i.e. canopy temperature depression (CTD recorded separately at three growth stages), Normalized difference vegetation index (recorded separately at three growth stages) and membrane thermostability were studied in late sown conditions during rabi2017-18. The method for recording these physiological traits is described below.

\section{Canopy temperature depression (CTD)}

The ambient temperature and canopy temperature of whole plant was taken between 1200 hours and 1400 hours at heading stage of the crop. Canopy temperature depression (CTD) is the difference between ambient temperature and canopy temperature. CTD was measured with the help of Infra-red thermometer. Canopy temperature depression: Canopy temperature depression was recorded at 10 days interval. In which first reading was recoded at 50 percent flowering (CTD-I), second at 10 days after 50 percent flowering (CTD-II) and third at 20 days after 50 percent flowering (CTD-III),

\section{Normalized difference vegetation index (NDVI)}

Observation collected using green seeker instrument at different stages of the crop plant. The observations were taken at $50 \%$ flowering stage (NDVI-I), at 10 days after $50 \%$ flowering stage (NDVI-II), at 20 days after $50 \%$ flowering stage (NDVI-III).

\section{Membrane thermostability}

Leaf samples were taken from the uppermost fully expanded leaves and $3-5 \mathrm{~cm}$ long segments were excised from each of 10 healthy seedlings from each replication per genotype. For removal of any adherent these samples were rinsed twice with deionized water, and placed in $22 \times 150 \mathrm{~mm}$ test tubes with $10 \mathrm{ml}$ of deionized water. The test tube was covered with an aluminium foil. Severe heat stress was applied by submerging test tubes to a depth equal to the height of water in tubes (about $4 \mathrm{~cm}$ ) in a water bath at $49^{\circ} \mathrm{C}$ for 30 minutes. After that, the test tubes were held over night at room temperature. Very next day, electrical conductivity of each test tube sample was measured with an electrical conductivity meter after standardizing it with a $\mathrm{KCl}$ solution. Then the kill the leaf tissues of the test tubes were then autoclaved for ten minutes at $120^{\circ} \mathrm{C}$ and $0.10 \mathrm{MPa}$ and their conductance was measured again as an indication of the maximum potential leakage from a given sample (Ibrahim et al., 2001)..

Membrane thermostability was calculated by using the following formula (Sullivan 1972):

$\mathrm{MTS}=\left(1-\frac{\mathrm{T} 1}{\mathrm{~T} 2}\right) \times 100$

Where, T1 and T2 are the conductivity readings before and after autoclaving, respectively.

Observations were statistically analysed with the help of OPSTAT for genetic variability parameter to determine allelic diversity(Johnson et al., 1955; Burton 1952).

\section{Results and Discussion}

The analysis of variance for different morphophysiological characters is presented in Table 2. The results showed highly significant difference for most of the characters under study among twenty genotypes. This suggested that there is an inherent genetic difference among the genotypes.

Physiological traits revealed relative importance of their contribution towards 
terminal heat tolerance. Canopy temperature depression and normalized difference vegetation index exhibited the same trend with respect to different growth stages (Singh and Jaiswal, 2013; Abdipur et al., 2013) As the crop matures the depression value goes on decreasing because canopy gets hotter and results in lower photosynthetic assimilation which leads to lower yield (Fig. 1). NDVI reflects the chlorophyll content in the plant. As the crop matures or plant gets under heat stress, there is breakdown of chlorophyll present in the leaves (Dwivedi et al., 2003). The genotypes showing higher NDVI values will result in greater photosynthetic accumulation and tolerance to heat stress (Fig. 2). Membrane thermostability represents the ability of cell membrane to resist leakage of solutes from the cells. The genotypes exhibiting more leakage of solutes were mainly heat sensitive genotypes (Reynoldas $e t$ al., 1994, Abdipur et al., 2013; Rehman et al., 2016).

An assessment of genetic variability revealed that there was an ample amount of genetic variation among the genotypes. In general values of phenotypic coefficient of variation $(\mathrm{PCV})$ were found higher than their respective genotypic coefficient of variation (GCV) indicating the considerable influence of environment in the performance of these genotypes. For all characters under study, PCV was found slightly higher than GCV in each case, revealing the prominent role of environment in the expression of these characters. The estimates of range, mean, PCV, GCV, heritability (broad sense) and genetic advance are presented in Table 3. The characters like canopy temperature depression (I, II \& III), exhibited higher values of phenotypic variance while other traits also showed similar trend. This suggests that there is a good scope of selection for these factors (Singh et al., 2007; Dwivedi et al., 2003). The phenotypic coefficient of variation was higher than their respective genotypic coefficient of variation for all the traits (Dixit 1990; Singh et al., 2008; Tripathi et al., 2015). Canopy temperature depression showed maximum phenotypic coefficient of variation. This variation was minimum for days to maturity (Porwal et al., 2006; Jaiswal et al., 2010).

Estimates of phenotypic variance $(\sigma 2 p)$ were higher than genotypic variance $(\sigma 2 \mathrm{~g})$ (Table $2)$. A wide range of $(\sigma 2 p)$ was observed for canopy temperature depression (I, II \& III) while moderate range of variance showed by the traits number of tillers per plant spike length, NDVI III and thermostability at different physiological stages. The result of phenotypic coefficient of variation revealed that CTD-III exhibited highest phenotypic coefficient of variation (43.37) followed by CTD-II (33.21). Also CTD-I at different stages showed wide phenotypic coefficient of variation while, the remaining characters showed moderate to low phenotypic coefficient of variation.

Genotypic coefficient of variation was high for CTD-III (33.99) followed by yield per plant (26.61). Also chlorophyll content and CTD at different stages showed wide genotypic coefficient of variation. And remaining characters showed moderate to low genotypic coefficient of variation [Panwar and Singh (2000); Ali et al., (2008), Arvind and Raj (2015)]. The minimum value of genotypic coefficient of variation was observed for days to anthesis, days to maturity and CTD. Thus, the traits with high GCV are to be considered during selection (Arya and Jaiswal, 2015).

Similar studies with respect to PCV and GCV were carried out by various workers.High genotypic and phenotypic coefficient of variation for canopy temperature depression (at anthesis), canopy temperature depression (at 10 days after anthesis) was also in agreement with Gowda et al., (2011). The 
substantial differences observed between genotypic and phenotypic coefficient of variation showed the effect of environment in determining the total phenotypic variation Jaiswal et al., (2010). High estimates of genotypic and phenotypic coefficient of variation for canopy temperature depression (III) suggest sufficient variability, therefore offers scope of genetic improvement of the character through selection.

The heritability ranged from 52.02 percent to 97.1 percent. High heritability estimate was exhibited by membrane thermostability (93.35), NDVI-III (87.10), NDVI-I (8.10) and NDVI-II (85.77). The remaining traits showed moderate levels of heritability (Dwivedi et al., 2003; Atta et al., 2008; Zecevic et al., 2010).
The estimates of heritability alone cannot predict the response to selection. Heritability estimates appear to be more meaningful when accompanied by the estimates of genetic advance than alone (Johnson et al., 1955). Thus genetic advance has an added edge over heritability as a guiding factor to breeders in various selection programmes. Genetic advance expressed as a percentage of mean was observed to be high (>50\%) for canopy temperature depression (CTD I) and membrane thermostability (Zecevic et al., 2010, Rehman et al., 2016). Genetic advance coupled with high heritability was reported for canopy temperature depression and membrane injury percentage (Kumar et al., 2016; Gowda et al., 2011), which is in conformity with the present findings.

Table.1 List of wheat genotypes used in the experiment

\begin{tabular}{|c|l|c|l|c|l|}
\hline S. No. & Genotype & S. No. & Genotype & S. No. & Genotype \\
\hline $\mathbf{1}$ & PBN-51 & 15 & HD2864 & $\mathbf{2 9}$ & IC252874 \\
\hline $\mathbf{2}$ & BWL-0814 & 16 & RAJ4083 & $\mathbf{3 0}$ & IC212185 \\
\hline $\mathbf{3}$ & BWL-1771 & 17 & DBW-14 & $\mathbf{3 1}$ & SALEMBO \\
\hline $\mathbf{4}$ & BWL-9022 & 18 & BARKAEE & $\mathbf{3 2}$ & ARIANA66 \\
\hline $\mathbf{5}$ & BWL-0924 & 19 & Giza168 & $\mathbf{3 3}$ & GIZA155 \\
\hline $\mathbf{6}$ & BWL-1793 & 20 & IC32586 & $\mathbf{3 4}$ & BACANORA88 \\
\hline $\mathbf{7}$ & CUS/79/PRULLA & 21 & K9465 & $\mathbf{3 5}$ & IC118737 \\
\hline $\mathbf{8}$ & IEPACA RABE & 22 & RAJ4037 & $\mathbf{3 6}$ & C-306 \\
\hline $\mathbf{9}$ & SIDS1 & 23 & TEPOKO & $\mathbf{3 7}$ & HD2967 \\
\hline $\mathbf{1 0}$ & SUNSTAR & 24 & BABAX & $\mathbf{3 8}$ & PBW343 \\
\hline $\mathbf{1 1}$ & CHIRYA-3 & 25 & OTHERI EGYPT & $\mathbf{3 9}$ & RAJ3765 \\
\hline $\mathbf{1 2}$ & DHARWAD DRY & 26 & IC532653 & $\mathbf{4 0}$ & WH730 \\
\hline $\mathbf{1 3}$ & HD3086 & 27 & SERI82 & & \\
\hline $\mathbf{1 4}$ & HI1563 & 28 & SONORA64 & & \\
\hline & & & & & \\
\hline
\end{tabular}


Table.2 Analysis of variance for different characters

\begin{tabular}{|c|c|c|c|c|c|c|c|c|c|c|c|c|c|c|c|}
\hline Source & & \multicolumn{14}{|c|}{ Mean squares of morpho-physiological traits } \\
\hline Character & d.f. & DH & DM & GFD & TILLER & SL & GY & TKW & CTD I & CTD II & CTD III & NDVI I & NDVI II & NDV III & MSI \\
\hline Replication & 2 & 1.13 & 2.16 & 1.26 & 1.98 & 0.01 & 2.06 & 1.56 & 0.54 & 2.29 & 2.21 & 1.76 & 1.45 & 3.66 & 0.82 \\
\hline Treatments & 39 & $3.87 * *$ & $6.04 *$ & $8.05 * *$ & $19.38 * *$ & $8.27 * *$ & $7.22 * *$ & $31.45 * *$ & $10.83 * *$ & $8.48 * *$ & $6.01 * *$ & $56.98 * *$ & $107.28 * *$ & $262.66 * *$ & $205.88 * *$ \\
\hline Error & 78 & 0.7 & 1.55 & 1.16 & 1.74 & 0.93 & 1.07 & 1.13 & 1.9 & 1.99 & 1.04 & 2.68 & 5.62 & 2.62 & 1.85 \\
\hline
\end{tabular}

DH-Days to heading, DM- Days to maturity, GFD- Grain filling duration, TILLER- Number of tillers per plant, SL-

Spike length (cm), GY- Grain yield per plant (g)TKW-1000-kernel weight, MSI- Membrane thermostability

Table.3 Estimates of parameter of variability for wheat genotypes

\begin{tabular}{|c|c|c|c|c|c|c|c|c|c|c|c|c|c|c|c|}
\hline Traits & & DH & $\mathrm{DM}$ & GFD & TILLER & SL & GY & TKW & CTD I & CTD II & CTD III & NDVI I & $\begin{array}{c}\text { NDVI } \\
\text { II }\end{array}$ & NDV III & MSI \\
\hline Mean & & 78.07 & 111.17 & 33.10 & 9.79 & 10.65 & 21.82 & 35.56 & 7.26 & 6.09 & 3.83 & 0.75 & 0.64 & 0.45 & 30.95 \\
\hline S.E(m) & & 0.48 & 0.42 & 0.62 & 0.42 & 0.82 & 0.77 & 0.21 & 0.79 & 0.52 & 0.12 & 0.47 & 0.47 & 0.46 & 0.53 \\
\hline \multirow[t]{2}{*}{ Range } & Max & 75.33 & 108.67 & 29.12 & 5.67 & 6.33 & 19.30 & 29.65 & 5.56 & 3.39 & 0.58 & 0.67 & 0.43 & 0.22 & 14.89 \\
\hline & Min & 84.67 & 118.33 & 39.33 & 15.33 & 15.17 & 24.31 & 40.95 & 9.78 & 8.32 & 6.97 & 0.83 & 0.74 & 0.62 & 49.64 \\
\hline $\mathrm{PCV}(\%)$ & & 1.71 & 1.39 & 5.63 & 28.19 & 17.26 & 8.10 & 9.45 & 30.41 & 33.21 & 43.37 & 6.05 & 9.94 & 20.89 & 26.97 \\
\hline $\mathrm{GCV}(\%)$ & & 1.32 & 1.22 & 4.59 & 24.76 & 14.69 & 6.57 & 8.96 & 23.76 & 23.95 & 33.99 & 5.65 & 9.20 & 20.58 & 26.61 \\
\hline $\operatorname{ECV}(\%)$ & & 1.08 & 0.67 & 3.26 & 13.47 & 9.06 & 4.74 & 3.00 & 18.98 & 23.01 & 26.94 & 2.17 & 3.75 & 3.58 & 4.39 \\
\hline \multicolumn{2}{|c|}{ Heritability $h^{2}$ bs (\%) } & 60.15 & 76.83 & 66.46 & 77.16 & 72.46 & 65.72 & 89.94 & 61.04 & 52.02 & 61.42 & 87.10 & 85.77 & 97.07 & 97.35 \\
\hline \multicolumn{2}{|c|}{ Expected GA (\%) } & 2.11 & 2.21 & 7.70 & 44.81 & 25.76 & 10.96 & 17.50 & 38.24 & 35.59 & 54.87 & 10.86 & 17.56 & 41.78 & 54.09 \\
\hline
\end{tabular}

DH-Days to heading, DM- Days to maturity, GFD- Grain filling duration, TILLER- Number of tillers per plant, SLSpike length (cm), GY- Grain yield per plant (g)TKW-1000-kernel weight, MSI- Membrane thermostability 


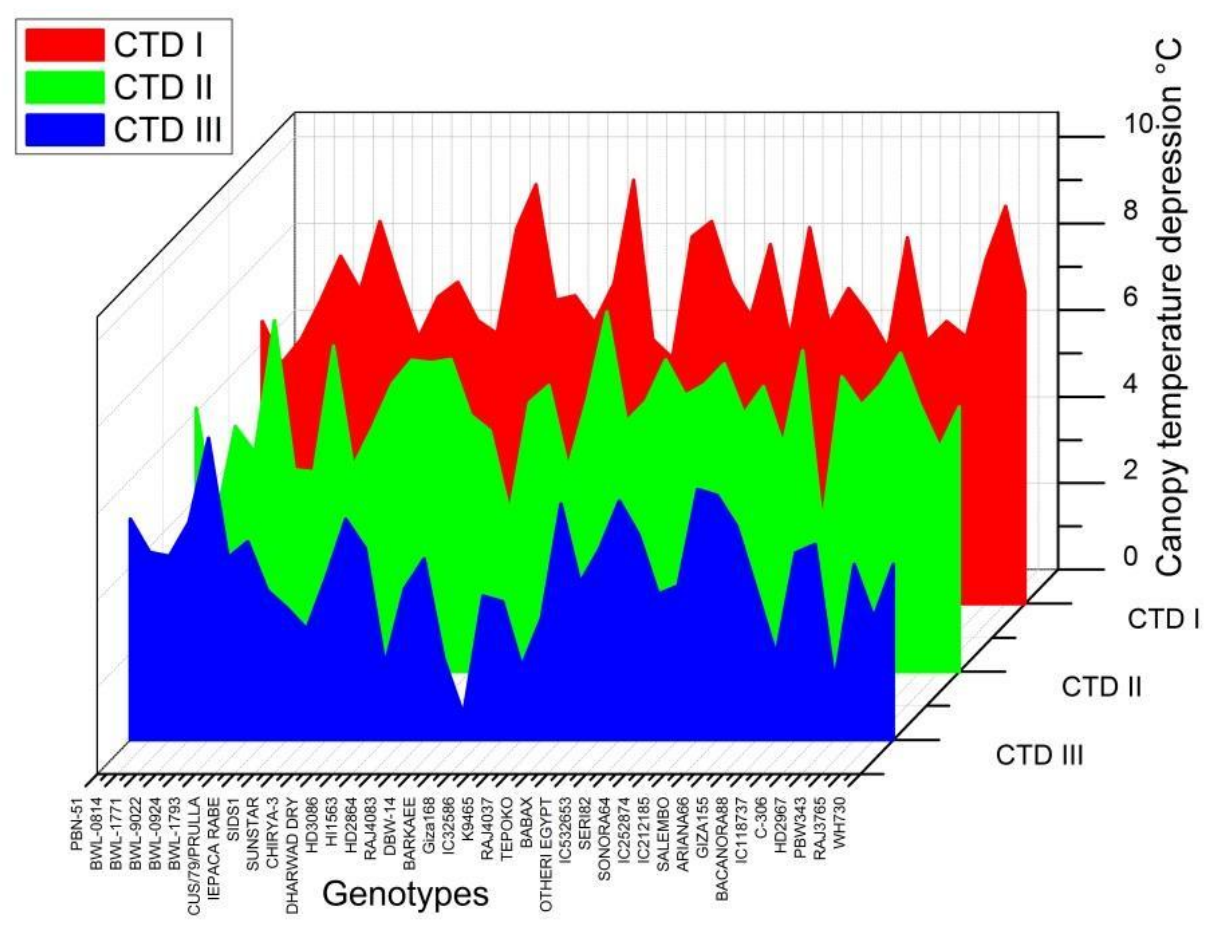

Fig.1 Comparative presentation of Canopy temperature depression at different growth

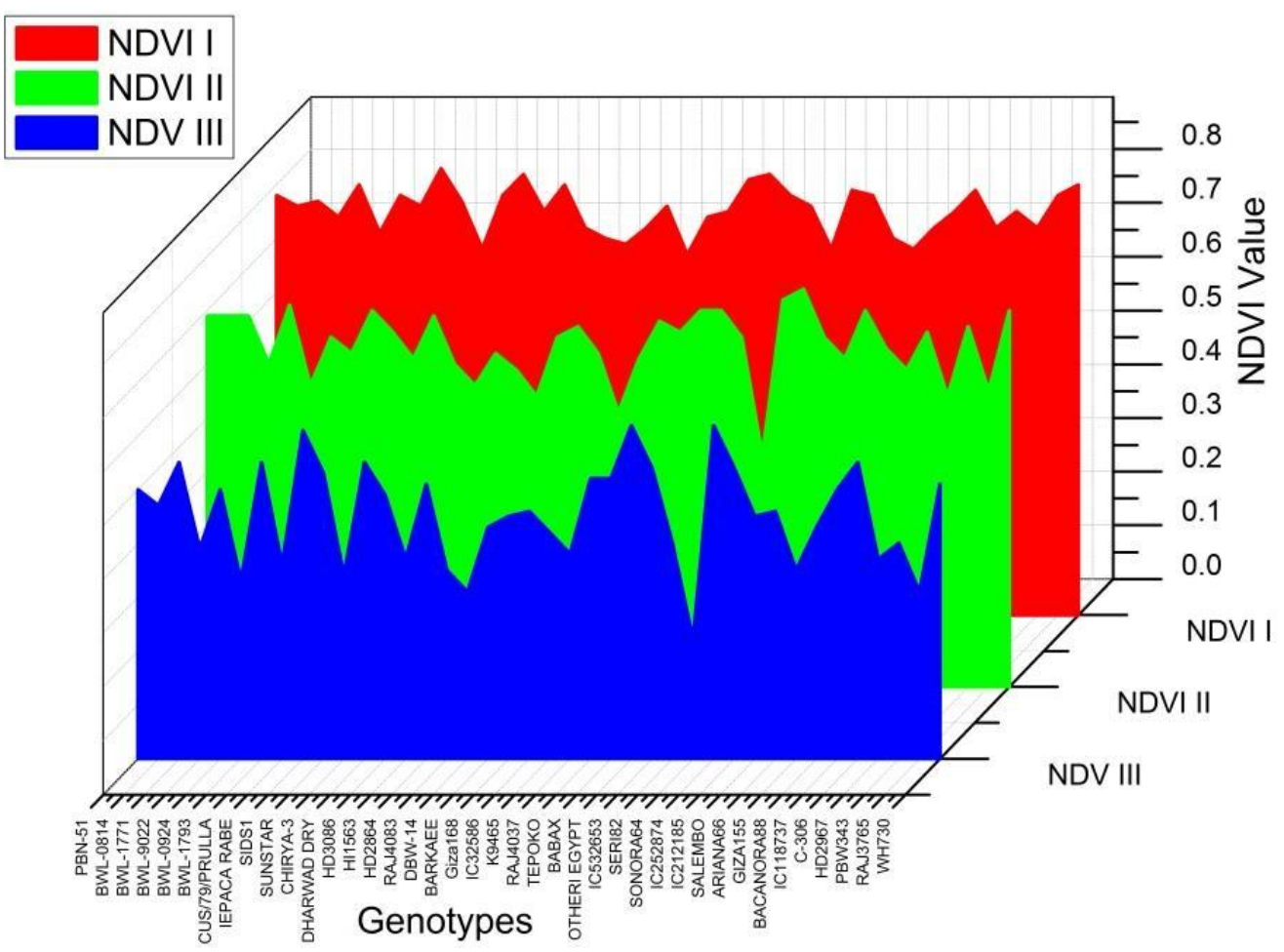

Fig.2 Comparative presentation of chlorophyll content (NDVI value) at different growth 
Moderate estimate of genetic advance (25\%$50 \%$ ) was reported for number of tillers per plant, NDVI I, CTD (I \& II) and spike length, whereas low estimate of genetic advance was reported for rest of the traits like grain yield per plant and 1000 kernel weight (Singh et al., 2008; Tripathi et al., 2015; Zecevic et al., 2010).To predict the reliable estimates of additive or non-additive effects, heritability should be considered in conjugation with genetic advance (Burton 1952, Johnson et al., 1955). High heritability with high genetic advance was found for membrane thermostability indicated the additive effect of genes and selection may be effective for the trait. High heritability with moderate genetic advance was reported by NDVI, grain weight per spike and flag leaf length, which revealed the presence of both additive and non-additive gene effects (Soumitra et al., 2016). However, traits like 1000 kernel weight, NDVI (II \&III) with high heritability and low genetic advance indicated the role of non-additive gene action (Reynoldas et al., 1994). Thus improvement of such traits was suggested through hybridization followed by selection.

In conclusion, climate change and sustainable development are interlinked problems that pose a serious challenge to humanity. High temperature stress in the recent years has been major factor affecting the wheat productivity. The selection of wheat genotypes with better grain yield and tolerance is the principal aim of wheat production. It can be concluded from the above mentioned findings that the genotypes used in the study exhibited considerable variability for various morphophysiological traits under study, thus providing the ample scope for selection of elite genotypes which can be further utilised for developing thermotolerant cultivars. Physiological traits i.e. canopy temperature depression, chlorophyll content and memberane thermostability exhibited higher than their corresponding genotypic coefficient of variation, it can be interpreted as less difference in the estimates of genotypic and phenotypic variance reflected little influence of environment on these traits. Higher genotypic variances compared to environmental variances for all the characters suggested that the variability present among the genotypes were mainly due to genetic reason with minimum influence of environment and hence heritable. These physiological traits exhibited high genetic gain, which indicates that these traits will directly respond to selection due to presence of additive genes. So, formulating a selection criterion for developing thermotolerant cultivars these physiological traits must be kept in mind. These physiological traits can be coupled in addition to morphological traits for developing thermotolerant cultivars.

\section{Acknowledgments}

Authors are thankful to Director Research, G. B. Pant University of Agriculture and Technology, Pantnagar-263 145 (Uttaranchal, India) for providing research facilities and Washington State University, Pullman, USA for sharing the research material. Work on plant stress tolerance in laboratory is partially supported by Department of Biotechnology (DBT), Government of India.

\section{References}

Abdipur, M., Ramezani, H.R., Bavei, V. and Talaee S. 2013. Effectiveness of Canopy Temperature and Chlorophyll Content Measurements at Different Plant Growth Stages for Screening of Drought Tolerant Wheat Genotypes. American-Eurasian J. Agric. \& Environ. Sci., 13 (10): 1325-1338

Ali, Y., Atta, B.M., Akhter, J., Monneveux, P., Zahid, L. 2008. Genetic variability, association and diversity studies in wheat (Triticum aestivum L.) 
germplasm. Pakistan Journal of Botany., 40(5): 2087-2097.

Almeselmani, M., Deshmukh, P.S., Chinnusamy, V. 2012. Effect of prolong high temperature stress on respiration, photosynthesis and gene expression in wheat (Triticum aestivum $\mathrm{L}$.) varieties differing in their thermotolerance. Plant Stress. 6:2532.

Arvind, K., Raj, S. 2015. Genetic variability in relation to qualitative and quantitative traits in wheat (Triticum aestium L.). Agrica Journal 3(2): 2328.

Arya, M. and Jaiswal, J.P. 2015.Screening for heat tolerance in wheat germplasm by applying physiological and biochemical indices. Electronic Journal of Plant Breeding, 6(1): 341349

Atta, Y.A., Akhter, B.M.J,, Lateef, P.Z. 2008.Genetic variability, association and diversity studies in wheat (Triticum aestivum L.) germplasm. Pakistan Journal of Botany 40(5): 2087-2097.

Burton, G.W. and Vane, E.W. 1953. Estimating heritability in tall Fescue (Festucaarund inacea) from replicated colonal material. Agronomy Journal. 45: 478-481.

Dixit, S.K. 1990.Variability pattern in durum wheat under different sowing path analysis inland races of bread wheat from South Western Iran. Euphytica 41: 183-190.

Dwivedi, V.K., Kumar, S., Tyagi, N.K. 2003.Genetic variability in some metric traits and it contribution to yield in wheat (Triticum aestivum L.). Progressive Agriculture, 3(1/2): 152153.

Fischer, G., Shah, M. and Van, V. H. 2002. Climate change and agricultural vulnerability. World summit on sustainable development,

Johannesburg.

Gowda, D.S., Singh, G. P. and Singh, Anju M. (2011). Relationship between canopy temperature depression, membrane stability, relative water content and grainyield in bread wheat (Triticum aestivum) under heat-stress environments. Ind. J. Agri. Sc. 81(3):197-202.

Ibrahim, A. M. H., Quick, J. S. 2001.Heritability of heat tolerance in winter and spring wheat. Crop Sci., 41: 1401-1405.

ICAR-IIWBR，2017.Director's Report of AICRP on Wheat and Barley Improvement Project 2016-17. Ed: G. P. Singh, ICAR-Indian Institute of Wheat and Barley Research, Karnal, India., P.87.

Intergovernmental Panel on Climate Change (IPCC) Climate change 2007-The physical science basis. In Contribution of Working Group I to the Fourth Assessment Report of the Intergovernmental Panel on Climate Change; Cambridge University Press: Cambridge, UK, 2007.

Jaiswal J.P., Arya M., Kumar A., Swati and Rawat R.S. 2010. Assessing genetic diversity for yield and quality traits in indigenous bread wheat germplasm. Electronic Journal of Plant Breeding, 1(4): 370-378.

Jaiswal, J.P., Bhowmick P.K. and Grover, A. 2010. Selection of bread wheat genotypes for heat tolerance based on physiological traits and heat shockproteins.8th International Wheat Conference, June 1-4, St. Petersberg, Russia.

Johnson, H.W., Robinson, H.F. and Comstock, R.E. 1955. Estimates of genetic and environmental variability in soybeans. Agronomy Journal.47: 314-318 
Kahrizi, D., Cheghamriza, K., Kakaei, M., Mohammadi, R., Ebadi, A. 2010.Heritability and genetic gain of some morpho-physiological variables of durum wheat (Triticum turgidum var. durum). Afr. J. Biotechnol., 9(30): 4687- 4691.

Kosina, P., Reynolds, M.P., Dixon, J., Joshi, A. 2007.Stakeholder perception of wheat production constraints, capacity building needs, and research partnerships in developing countries. Euphytica. 2007; 157: 475483.

Kumar, A., Swati, Jaiswal, J.P., Bharati, A. and Goel, P. 2016.Characterization of wheat genotypes using morphophysiological traits for heat tolerance. Applied Biological Research, 18(2): 815.

Lane, A., Jarvis, A. 2007. Changes in Climate will modify the Geography of Crop Suitability: Agricultural Biodiversity can help with Adaptation. eJournal. 4: $1-12$

Memon, S.M., Qureshi, M.U., Ansari, B.A. and Sial, M.A. 2007.Genetic heritability for grain yield and its related characters in spring wheat. Pak. J. Bot. 39 (5):1503- 1509

Panwar, D., Singh, I. 2000. Genetic variability and character association of some yield components in winter $\mathrm{x}$ spring nursery of wheat. Advances in Plant Science, 8(1): 95-99.

Porwal, Y., Prasad, S.V.S., Billore, M. 2006.Association of path analysis for grain yield, its components and quality traits in bread wheat. National Journal of Plant Improvement 8(1): 24-27.

Rane J, Shoran J, Nagarajan S.2000. Heat stress environments and impact on wheat productivity in India: Guestimate of losses. Indian Wheat News Letter. 2000; 6:5-6.

Rehman, U.R., Muhammad, B., Rashid M.R.,
Tahir, M.N., Muhammad, K.N.S., Habtamu, A., and Guijun, Y. 2016.Cell membrane stability and chlorophyll content variation in wheat (Triticum aestivum) genotypes under conditions of heat and drought. Crop and Pasture Science. 67(7): 712-718.

Reynolds, M. P. 1994. Summary of data from the 1st and 2nd International Heat Stress Genotype Experiment. In : Saunders, D. A. and Hettel, G. P. eds. Wheat in Heat Stressed Environments: Irrigated, Dry Areas and Rice Farming Systems. Proceedings of the International Conference, Wheat in Hot, Dry, Irrigated Environments. Mexico, D.F.: CIMMYT.

Reynolds, M. P., Nagarajan, S., Razzaque, M. A. and Ageeb, O.A. A. 2001. Heat tolerance. In: Reynolds M P, Ortiz Monasterio J I and McNab A(ed) Application of Physiology in Wheat Breeding. Pp. 124-35. CIMMYT, Mexico.

Shiferaw, B., Smale, M., Braun, H.J., Duveiller, E., Reynolds, M., Muricho, G. 2013. Crops that feed the world 10.Past successes and future challenges to the role played by wheat in global food security. Food Security. 5: 291-317.

Singh, J.P, Prasadm, S., Singh, K.N., Singh, R. 2007.Screening of heat tolerant wheat varieties by membrane thermo stability index in relation to yield and yield attributing traits. International Journal of Plant Sciences. 2(2): 159165.

Singh, N.B., Singh, Y.P., Tiwari, L.P., Bahar, J., Singh, V.P.N., et al., (2008). Morphophysiological traits as index of screening wheat genotypes for thermotolerance. Indian Journal of Plant Physiology 13(3): 307-311

Singh, P. and Jaiswal, J.P. 2013. Assessment of genetic diversity in Bread wheat 
(Triticumaestivum L. em. Thell), genotypes based on agromorphological traits using Mahalanobis ' $\mathrm{D}^{2}, \quad$ statistic. Environment and Ecology, 31(2A): 679-682.

Soumitra.M., Mukherjee, S., Mukhopadhyaya, S. K., Dash, A. P. 2016.Genetic variability, correlation and path analysis of bread wheat (Triticum aestivum L.) Genotypes under terminal heat stress. International Journal of Bio-Resource \& Stress Management .7(6): 12381245

Sullivan, C.Y. 1972.Mechanism of heat and drought resistance in grain sorghum and methods of measurement. In: Sorghum in the seventies", N. G. P. Rao and L. R. House (eds.), Oxford and IBH publishing Co. New Delhi, India. 1972.

Tripathi, G.P., Parde, N.S., Zate, D.K., Lal,
G.M. 2015.Genetic variability and heritability studies on bread wheat (Triticum aestivum L.).International Journal of Plant Sciences. 10(1/2): 5759.

USDA. 2017. World agricultural production. Washington, DC, USA: UnitedStates Department of Agriculture Foreign Agricultural Service.

Wardlaw, I.F., Dawson, I.A., Munibi, P. and Fewster, R. 1989. The tolerance of wheat to high temperatures during reproductive growth. I. Survey procedures and general response patterns. Aust J Agr Res., 40: 1-13.

Zecevic, V., Boskovic, J., Dimitrijevic, M., Petrovic, S. 2010.Genetic and phenotypic variability of yield components in wheat (Triticum aestivum L.). Bulgarian Journal of Agricultural Science 16(4): 4.

\section{How to cite this article:}

Devender Sharma, J.P. Jaiswal, N.K. Singh, Anjana Chauhan and NavinChanderGahtyari. 2018. Developing a Selection Criterion for Terminal Heat Tolerance in Bread Wheat Based on Various Mopho-Physiological Traits. Int.J.Curr.Microbiol.App.Sci. 7(07): 2716-2726. doi: https://doi.org/10.20546/ijcmas.2018.707.318 